\title{
Rice Cooking Quality and Physico-Chemical Characteristics: a Comparative Analysis of Selected Local and Newly Introduced Rice Varieties in Ebonyi State, Nigeria
}

\author{
Oko A. O. ${ }^{1}$, Ubi B. $\mathbf{E}^{1,2 . *}$, Dambaba $\mathbf{N}^{3}$ \\ ${ }^{1}$ Department of Biotechnology, Ebonyi State University, P.M.B. 053 Abakaliki, Ebonyi State, Nigeria \\ ${ }^{2}$ Biotechnology Research and Development Centre, Ebonyi State University, P.M.B. 053 Abakaliki, Ebonyi State, Nigeria \\ ${ }^{3}$ Cereal Services Laboratory, National Cereals Research Institute (NCRI), Badeggi, P.M.B.8 Bida, Niger State, Nigeria
}

\begin{abstract}
The Choice of rice varieties by farmers and consumers and the rate at which farmers in Ebonyi state go for new rice varieties at the expense of indigenous varieties have become a source of worry to scientists in Nigeria. We assessed the cooking quality and physico-chemical characteristics of 15 selected indigenous and five newly introduced hybrid rice varieties grown in Ebonyi State, Nigeria. Significant variation $(\mathrm{P}<0.05)$ was detected among the 20 rice varieties for all the traits evaluated. The results showed that all the five newly introduced hybrid rice varieties do not swell appreciably during cooking. The grains of Cv. "China" had the highest elongation values of $3.2 \pm 0.00 \mathrm{~mm}$. "E4197" has the best physical appearance but easily dissolves in water during cooking. Most of the physico-chemical characteristic such as amylose, amylopectin, gel consistency and gelatinization temperature were significantly correlated (positively or negatively) with some of the cooking quality traits (elongation during cooking, solids in cooking water and optimum cooking time), indicating that efforts aimed at selecting rice varieties with improved cooking quality traits would warrant a consideration of the physico-chemical attributes of the rice grain. The overall cooking quality and physico-chemical attributes of some of the indigenous rice varieties were even relatively better than the newly introduced hybrid varieties. Farmers should, therefore, be critical in accepting new varieties that may not be comparably outstanding in cooking quality and physico-chemical characteristics, in order to preserve the integrity of the all-cherished indigenous rice varieties of Ebonyi State, Nigeria.
\end{abstract}

Keywords Rice, Local and New Hybrid Varieties, Cooking Quality, Physico-Chemical Traits

\section{Introduction}

Rice is a food crop of world-wide importance and forms the foundation of the diet of over 3 billion people, constituting over half of the world's population[1]. It is widely cultivated throughout the world and has become the second most important cereal in the world after wheat in terms of cultivation, due to a recent decline in maize production[2]. It is utilized mostly at the household level, where it is consumed as boiled or fried with stew as in Nigeria. Different cultures have different preferences regarding the taste, texture, colour and stickiness of the rice varieties that they consume. For example, dry flaky rice is eaten in South Asia and the Middle East; moist sticky rice in Japan, Taiwan Province of China, the Republic of Korea, Egypt and northern

* Corresponding author:

ubi.benjamin@yahoo.com (Ubi B. E.)

Published online at http://journal.sapub.org/fph

Copyright (C) 2012 Scientific \& Academic Publishing. All Rights Reserved
China; and red rice in parts of southern India. Many countries have signature rice recipes, such as sushi, fried rice, curry, paella, risotto, pancit, and beans with rice. There are also many sweets and candies made from rice.

The agronomic classification of rice into glutinous and non-glutinous or translucent rice includes qualitative characteristic of the endosperm. The glutinous rice type is by far the most important; accounting for about $90-100 \%$ of the total in different countries. The non-glutinous type is not sticky when cooked while the glutinous types have a soft endosperm that is composed of dextrin instead of starch. When cooked, they become sticky but are more preferred by some people due to softness after cooking. Fat content is higher in non-glutinous rice than glutinous rice and the protein content is lower in the glutinous than in the non-glutinous rice type. Varieties of rice are classified according to cooking properties on the basis of gelatinization temperature[3].

Pomeranz[4] reported that rice composition differs according to the variety and processing method used. Among 
the many forms which rice is processed, parboiling of rice is widely used which is the hydrothermal treatment of raw rice prior to milling. The quality of milled parboiled rice is being assessed based on physical parameters like degree of milling, percentage head rice, broken grain, chalkiness, red streak grain, grain size, colour, and shape at $1000 \mathrm{~g}$ weight. Except for Burkina Faso and Niger, rice is a staple crop throughout West Africa, especially in Cote d'lvoire, the Gambia, Guinea, Guinea Bissau, Liberia, Senegal and Sierra Leone. The River Niger drainage system is a major rice-growing environment in the region. Nigeria has a leading role in rice production in West Africa, ranking highest as both the producer and consumer of rice in the sub-region with production figures slightly above $50 \%[5]$.

The economic value of rice depends on its cooking and processing quality, which can be measured in terms of water uptake ratio, grain elongation during cooking, solids in cooking water and cooking time. Rice varieties with amylose content of more than $25 \%$ absorb more water and have a fluffy texture after cooking[6]. Within an individual rice particle, various processes occur during cooking. The heating, water uptake and swelling of the rice particle all involve diffusive processes. When water is present at sufficiently high temperatures, the starch undergoes a gelatinization reaction. Many rice studies have concentrated on the soaking of rice grains at fixed temperatures[7] or the parboiling process. For temperatures below $50^{\circ} \mathrm{C}$, the grains absorb a limited amount of water up to approximately $30 \%$ moisture content (wet basis). The resulting grains are not cooked because the starch has not undergone gelatinisation. From common experience with small samples, it is known that soaking rice grains in water at $25^{\circ} \mathrm{C}$ for about one hour is required before cooking at temperatures above $70^{\circ} \mathrm{C}$ for 20 minutes or more. As water is taken up by a rice particle, the starch granules undergo a gelatinization reaction, the term generally used to describe the swelling and hydration of the granular starch[8].

Linear elongation of rice on cooking is one of the major characteristics of good rice. Some varieties expand more in size than others upon cooking. Length-wise expansion without increase in girth is considered a highly desirable trait of high quality rice[9]. Soaked milled rice of high gelatinization temperature elongates less during cooking than low and intermediate gelatinizing rice. Thus, Gelatinization temperature correlates positively with grain elongation 10].

Thus far, most of the published research on cooking and eating qualities in rice have focused on physico-chemical properties i.e. amylose content (AC), Gel consistency (GC) and gelatinization temperature (GT) which are directly related to rice cooking quality. Apparently, the amylose content reported for rice samples ranges from $24.6-28.8 \%$ and the level vary within each location. Amylose consists of linearly linked glucose molecules and is relatively resistant to digestion, hence the term "resistant starch". This means that rice varieties with a greater proportion of starch in the form of amylose tend to have a lower glycemic index. Amylose content of milled rice has been found to correlate positively with hardness values of cooked rice and negatively with stickiness values[10]. Cooking quality of rice mainly depends on amylose content and gelatinization temperature. Amylose contents determine the texture of cooked rice. Rice varieties with amylose content of more than $25 \%$ absorb more water and have a fluffy texture after cooking.

Rice starch is usually digested quite rapidly, compared to other starchy foods such as noodles, sweet potato or cassava. This leads to a prompt and pronounced increase of the blood glucose level (= high glycemic index) after the ingestion of rice, similar to that of white bread or pure glucose[19]. Rapid starch digestion is regarded as unfavorable, because fast digestion can cause a sensation of hunger only shortly after the ingestion of rice, and the energy released is quickly used. Farmers cultivating rice landraces in the Philippines reported a relatively long feeling of satiation after the ingestion of certain varieties.

Consumers' choice of rice varieties are largely based on grain and cooking qualities. More so, the high rate of influx of hybrid varieties and other new rice varieties to local farmers who then abandon their hitherto cherished indigenous varieties without critical comparison is unacceptable. Rice quality differs according to the variety and processing method used[4]. The differences in quality which are mainly attributed to differences in colloidal structure and the extent of swelling of any variety of rice on cooking have always been used as index of its quality.

Traditionally, Ebonyi farmers are rice producers growing many varieties and prone to accepting any new varieties with seemingly better grain yield without considering other qualities. Therefore, there is need to assess the quality of new hybrid varieties being introduced into the state and compare them with the local varieties in order not to lose the already existing varieties which may be better than the new ones in overall merit. The overall objective of this study is to carry out a critical comparison of adapted indigenous and the newly introduced rice varieties in Ebonyi State with a view to determining their nutritional worth, and advising farmers and consumers accordingly. The specific objectives of this work is, therefore, to evaluate the grain quality characteristics such as cooking quality (e.g. water uptake ratio, grain elongation, cooking time and solids in cooking water), amylose, and amylopectin contents, gel consistency and gelatinization temperature of some local and some newly introduced hybrid rice varieties in Ebonyi State.

\section{Materials and Methods}

\subsection{Plant Materials}

A total of fifteen rice cultivars were collected from Ebonyi rice farmers at their farm sites during harvest: five rice cultivars from each of the three senatorial zones of Ebonyi State. In addition, five new hybrid rice varieties were collected from the Alliance for Green Revolution in Africa (AGRA) research project at the Biotechnology Research and Development Centre of Ebonyi State University, Abakaliki. The 
different rice cultivars were all planted and grown under the same conditions. At maturity, the rice grains were harvested, processed and taken to the Cereal Services Laboratory, National Cereals Research Institute, Badeggi, Niger state for the analysis of cooking quality and physico-chemical characteristics as described below.

\subsection{Analyses of Amylose and Amylopectin Contents}

The amylose and amylopectin were analyzed by published standard methods. The evaluation method described by Perez et al. [1987] was used to analyze amylose content while the amylopectin content was by the difference method.

\subsection{Characterization of Rice for Cooking Quality and other Physico-Chemical Parameters}

\subsubsection{Water Uptake Ratio}

This was determined by cooking $2.0 \mathrm{~g}$ of whole rice kernels from each treatment in $20 \mathrm{ml}$ distilled water for a minimum cooking time in a boiling water bath and draining the superficial water from the cooked rice. The cooked samples were then weighed accurately and the water uptake ratio was calculated as the ratio of final cooked weight to uncooked weight. Water uptake ratio $=$ (weight of cooked rice) / (weight of uncooked rice sample).

\subsubsection{Solids in Cooking Water}

This was determined by drying an aliquot of the cooking water in a tarred evaporating dish to evaporate the water as steam. The weight of the empty Petri dish was measured and recorded $\left(\mathrm{W}_{1}\right)$. This was followed by measuring the weight of the Petri dish and aliquot $\left(\mathrm{W}_{2}\right)$. The weight of the Petri dish and the dry aliquot was measured $\left(\mathrm{W}_{3}\right)$. The amount of solid in cooking water was now calculated as: $\mathrm{W}_{3}-\mathrm{W}_{1}$; where $\mathrm{W}_{1}=$ weight of empty Petri dish, $\mathrm{W}_{2}=$ weight of empty dish + dry aliquot $\left(\mathrm{W}_{3}\right)$.

\subsubsection{Cooking time}

This was determined by boiling $2.0 \mathrm{~g}$ of whole rice kernels from each treatment in $20 \mathrm{ml}$ distilled water, removing a few kernels at different time intervals during cooking and pressing them between two glass plates until no white core was left. Optimum cooking time was taken as the established cooking time plus two (2) additional minutes.

\subsubsection{Grain Elongation during Cooking}

This was determined by first measuring the initial grain length $\left(\mathrm{L}_{0}\right)$ before cooking. The final length $\left(\mathrm{L}_{0}\right)$ after cooking was then measured. The grain elongation during cooking was then calculated as: $\mathrm{L}_{1}-\mathrm{L}_{0}$, where $\mathrm{L}_{0}=$ initial grain length before cooking, $\mathrm{L}_{1}=$ final length after cooking.

\subsubsection{Gelatinization Temperature (GT)}

This was indexed by alkali spreading test [11]. The degree of spreading of individual milled rice kernel in a weak alkali solution $(1.7 \% \mathrm{KOH})$ at room temperature $\left(32 \pm 2^{\circ} \mathrm{C}\right)$ was evaluated on a 7-point numerical scale[12]. Each test was conducted three times, each time, 10 intact milled grains were placed on a petri dish to which $15 \mathrm{ml}$ of $1.7 \% \mathrm{KOH}$ was added. The grains were carefully separated from each other and incubated at ambient temperature for $23 \mathrm{hrs}$ to allow spreading of the grains. Grains swollen to the extent of a cottony center and a cloudy collar were given an alkali spread value (ASV) score 4 and used as check for scoring the rest of the samples in the population. Grains that were unaffected were given ASV of 1 and grains that were dispersed and disappeared completely were given a score of 7. A low ASV correspond to a high gelatinization temperature; conversely, a high ASV indicates a low GT.

\subsubsection{Gel Consistency}

This was determined based on the consistency of milled rice paste that has been gelatinized by boiling in dilute alkali and then cooled to room temperature. Tubes were laid horizontally on a table lined with millimeter graph paper and total length of the gel measured in millimeters

\subsection{Statistical Analysis}

All data were analyzed by the Analysis of Variance (ANOVA) procedure using SAS software version 9.1 (SAS Institute, 1998). Differences were declared statistically significant when $P \leq 0.05$. Where significant differences were detected, the means were separated by the least significant difference (LSD) at 5\% probability level. Interrelationships among traits values were estimated using the Pearson correlation coefficient.

\section{Results}

\subsection{Variation in Amylose, Amylopectin, Gel Consistency and Gelatinization Temperature (GT) Characteris- tics among the 20 Evaluated Rice Cultivars}

The values of the physico-chemical characteristics such as amylose, amylopectin, gel consistency and gelatinization temperature of the grain among the 20 cultivars used in this study is shown in Table 1. Highly significant variation ( $p<$ 0.0001 ) was observed among these four physico-chemical parameters. The amylose content among the varieties studied ranged between $19.50-25.51 \%$, with a mean value of $22.91 \pm 2.01 \%$. "Awilo" and "E4313" had the highest percentage of amylose, followed by Chinyereugo, E4077, E4212 and MASS II. On the other hand, Faro14 (I) and Faro14 (II) recorded the least value for percentage amylose (Table 1).

The values for amylopectin content ranged between $74.42-80.50 \%$, with a mean value of $75.95 \pm 9.45 \%$. "Faro14(I)" and "Faro14(II)" had the highest percentage of amylopectin, followed by "Mass III" and "Mass II" while "Awilo" and "Mass I" had the least percentage of amylopectin, followed by E4314, Chinyereugo, E4077 and E4212. "E4197", "Faro14 (II)" and "Onuogwu" had the highest values for gel consistency of 54.00, 53.33 and 53.33 
$\mathrm{mm}$, respectively; while "Faro15 (II)" had the least value of $43.00 \mathrm{~mm}$ followed by "E4077" (44.67 mm), "Mass (I)" $(48.67 \mathrm{~mm})$ and "China" $(47.67 \mathrm{~mm})$. The range of values was between $43.00-54.00 \mathrm{~mm}$ with a mean value of $49.7 \pm 2.97 \mathrm{~mm}$. The gelatinization temperature ranged from low to high. Majority of the farmers' varieties were of intermediate gelatinization temperatures, while three out of the five newly introduced hybrid varieties had low gelatinization temperatures.

\subsection{Variation in Cooking Quality Characteristics among the 20 Evaluated Rice Cultivars}

The rice cooking quality characteristics evaluated included water uptake ratio, grain elongation during cooking $(\mathrm{mm})$, solids in cooking water (g), and optimum cooking time (i.e. normal cooking time plus 2 min). Highly significant differences $(p<0.0001)$ were observed for these grain quality characteristics among the 20 cultivars used in this study (Table 2). "Faro15 (I)" had the highest value for water uptake followed by "China", while "Ezichi" had the least followed by "Mass I" and "Mass II". The range of values for water uptake ratio varied from 1.13-3.35 with a mean value of $2.24 \pm 0.56$. Other cultivars had relatively high values. The values of grain elongation during cooking among the varieties studied ranged between $1.08-3.20 \mathrm{~mm}$ with a mean value of $2.04 \pm 0.76 \mathrm{~mm}$. Grains of "China" variety had the highest elongation value, followed by "Sipi" and "Faro15 (II)", while "Canada" and "E4077" had the least values. It is worthy of note that all the newly introduced hybrid varieties showed very low values for grain elongation.

The values for solids in cooking water for all the varieties studied were between 0.01 and 1.05 with a mean value of $0.23 \pm 0.25$. "E4197" had the highest value for solids in cooking water followed by "Faro15 (II)", while "Faro15 (I)" showed the least value, followed by "Sipi", "Awilo", "E4314" and "Cooperative". The optimum cooking time similarly varied significantly among the rice cultivars ranging from 19 - 26 min with a mean value of $21.45 \pm 2.24$ min. "Awilo" and "FARO 15" took the longest time to cook, followed by "China" and Faro15 (I)", while "FARO 14(I)", "E4077", "E4212" took the shortest time interval to cook; and others took average time to cook.

Significant correlations were observed among the physico-chemical and grain quality attributes as shown in Table 3 . Water uptake ratio was significantly correlated with grain elongation during cooking, solids in cooking water, optimum cooking time, and gelatinization temperature, though the observed correlation coefficients were relatively low (Table $3)$. The positive direction in these observed correlations suggest that these grain quality attributes will simultaneously increase in rice cultivars having an increasing value for water uptake ratio. Similarly, significant correlations were detected between grain elongation during cooking and optimum cooking time $(r=0.478, p<0.0001)$, amylose content $(r=$ $0.380, p=0.003)$, and gel consistency $(r=0.299, p=0.020)$. The negative value of correlation between grain elongation during cooking and amylose content, indicates that cultivars that elongate more during cooking would likely have a decreased content of amylose. Furthermore, a significant but low correlation value was obtained between optimum cooking time and gelatinization temperature (Table 3). Significant but negative correlation values were obtained between amylose content with amylopectin and gel consistency, suggesting that rice cultivars selected for high amylose content may be invariably low in amylopectin content and gel consistency.

Table 1. Variation in Physico-chemical Characteristics Observed among the 20 Rice Cultivars*

\begin{tabular}{|c|c|c|c|c|c|}
\hline S/no. & Cultivar & Amylose (\%) & Amylopectin (\%) & Gel consistency $(\mathrm{mm})$ & Gelatinization behavior \\
\hline 1 & Awilo & $25.51^{\mathrm{A}}$ & $74.49^{\mathrm{A}}$ & $50.00^{\mathrm{DEF}}$ & Intermediate \\
\hline 2 & Canada & $21.32^{\mathrm{H}}$ & $78.68^{\mathrm{A}}$ & $49.00^{\mathrm{G}}$ & Intermediate \\
\hline 3 & Faro 15 (I) & $23.63^{\mathrm{F}}$ & $76.37^{\mathrm{A}}$ & $52.00^{\mathrm{BC}}$ & Intermediate \\
\hline 4 & Faro $14(\mathrm{I})$ & $19.55^{\mathrm{K}}$ & $80.45^{\mathrm{A}}$ & $49.33^{\mathrm{GHEF}}$ & Intermediate \\
\hline 5 & Sipi & $22.22^{\mathrm{G}}$ & $77.78^{\mathrm{A}}$ & $51.33^{\mathrm{DC}}$ & Low \\
\hline 6 & Faro 15(II) & $24.07^{\mathrm{E}}$ & $75.59^{\mathrm{A}}$ & $43.00^{\mathrm{L}}$ & Low \\
\hline 7 & Faro 14 (II) & $19.81^{\mathrm{K}}$ & $80.19^{\mathrm{A}}$ & $53.33^{\mathrm{BA}}$ & Intermediate \\
\hline 8 & China 4 & $24.39^{\mathrm{DE}}$ & $75.61^{\mathrm{B}}$ & $47.67^{\mathrm{J}}$ & Intermediate \\
\hline 9 & Chinyereugo & $25.00^{\mathrm{B}}$ & $74.95^{\mathrm{A}}$ & $53.00^{\mathrm{BA}}$ & Intermediate \\
\hline 10 & Mass1 & $20.24^{\mathrm{J}}$ & $79.7^{\mathrm{A}}$ & $48.67^{\mathrm{GHF}}$ & Low \\
\hline 11 & Onuogwu & $21.15^{\mathrm{H}}$ & $78.85^{\mathrm{A}}$ & $53.33^{\mathrm{BA}}$ & Low \\
\hline 12 & Cooperative & $23.10^{\mathrm{F}}$ & $76.90^{\mathrm{A}}$ & $50.33^{\mathrm{DE}}$ & Intermediate \\
\hline 13 & Mass (II) & $24.81^{\mathrm{BC}}$ & $74.42^{\mathrm{A}}$ & $47.00^{\mathrm{J}}$ & Intermediate \\
\hline 14 & Mass (III) & $20.66^{\mathrm{I}}$ & $79.34^{\mathrm{A}}$ & $48.33^{\mathrm{G}}$ & Low \\
\hline 15 & Ezichi & $21.41^{\mathrm{H}}$ & $78.59^{\mathrm{A}}$ & $52.33^{\mathrm{BC}}$ & Intermediate \\
\hline 16 & E4314 & $25.15^{\mathrm{BA}}$ & $74.85^{\mathrm{A}}$ & $49.00^{\mathrm{G}}$ & Low \\
\hline 17 & E4197 & $24.45^{\mathrm{DC}}$ & $75.55^{\mathrm{A}}$ & $54.00^{\mathrm{A}}$ & Low \\
\hline 18 & E4077 & $25.13^{\mathrm{B}}$ & $74.87^{\mathrm{A}}$ & $44.67^{\mathrm{K}}$ & Low \\
\hline 19 & E4212 & $24.87^{\mathrm{B}}$ & $75.13^{\mathrm{A}}$ & $48.00^{\mathrm{HJ}}$ & Intermediate \\
\hline \multirow[t]{4}{*}{20} & E4334 & $21.41^{\mathrm{H}}$ & $78.59^{\mathrm{A}}$ & $49.67^{\mathrm{GE}}$ & Intermediate \\
\hline & Mean SE & $22.91 \pm 2.01$ & $75.95 \pm 9.45$ & $49.7 \pm 2.97$ & \\
\hline & Pro. & 0.0001 & 0.0001 & 0.0001 & \\
\hline & $\mathrm{LSD}_{0.05}$ & 0.36 & 14.92 & 1.65 & \\
\hline
\end{tabular}

*Means followed with the same letter in each column are not significantly different $(\mathrm{p}<0.05)$. 
Table 2. Variation in Cooking Quality Characteristics Observed among the 20 Rice Cultivars Used in this Study*

\begin{tabular}{|c|c|c|c|c|c|}
\hline $\mathrm{S} / \mathrm{n}$ & Cultivar & Water uptake ratio & $\begin{array}{l}\text { Grain elongation dur- } \\
\text { ing cooking }(\mathrm{mm})\end{array}$ & $\begin{array}{l}\text { Solids in cooking } \\
\text { water }(\mathrm{g})\end{array}$ & $\begin{array}{l}\text { Optimum Cooking time } \\
\text { (i.e. }+2 \text { minutes) }\end{array}$ \\
\hline 1 & Awilo & $2.65^{\mathrm{C}}$ & $2.92^{\mathrm{D}}$ & $0.03^{\mathrm{JI}}$ & $26^{\mathrm{A}}$ \\
\hline 2 & Canada & $2.67^{\mathrm{C}}$ & $1.08^{\mathrm{L}}$ & 0.01 & $23^{\mathrm{ECD}}$ \\
\hline 3 & Faro $15(\mathrm{I})$ & $2.44^{\mathrm{ED}}$ & $2.62^{\mathrm{E}}$ & $0.06^{\mathrm{II}}$ & $24^{\mathrm{BC}}$ \\
\hline 4 & Sipi & $2.67^{\mathrm{C}}$ & $3.06^{\mathrm{B}}$ & $0.08^{Л \mathrm{JH}}$ & $20^{\mathrm{GF}}$ \\
\hline 5 & Faro $14(\mathrm{I})$ & $2.37^{\mathrm{E}}$ & $2.78^{\mathrm{D}}$ & $0.01^{\mathrm{J}}$ & $19^{\mathrm{G}}$ \\
\hline 6 & Mass III & $2.50^{\mathrm{D}}$ & $1.20^{\mathrm{K}}$ & $0.30^{\mathrm{F}}$ & $22^{\mathrm{ED}}$ \\
\hline 7 & Faro 14 (II) & $2.50^{\mathrm{D}}$ & $2.40^{\mathrm{F}}$ & $0.40^{\mathrm{D}}$ & $21^{\mathrm{ECD}}$ \\
\hline 8 & Faro 15 (II) & $3.30^{\mathrm{A}}$ & $3.00^{\mathrm{C}}$ & $0.70^{\mathrm{B}}$ & $26^{\mathrm{BA}}$ \\
\hline 9 & Chinyereugo & $2.30^{\mathrm{F}}$ & $2.60^{\mathrm{E}}$ & $0.20^{\mathrm{F}}$ & $22^{\mathrm{ECD}}$ \\
\hline 10 & China & $2.80^{\mathrm{B}}$ & $3.20^{\mathrm{A}}$ & $0.50^{\mathrm{C}}$ & $24^{\mathrm{BCD}}$ \\
\hline 11 & Onuogwu & $2.04^{\mathrm{H}}$ & $2.30^{\mathrm{G}}$ & $0.01^{\mathrm{J}}$ & $23^{\mathrm{ED}}$ \\
\hline 12 & Co-operative & $1.56^{\mathrm{I}}$ & $1.36^{\mathrm{JI}}$ & $0.10^{\mathrm{GIH}}$ & $20^{\mathrm{GF}}$ \\
\hline 13 & Mass (I) & $1.24^{\mathrm{J}}$ & $1.18^{\mathrm{K}}$ & $0.01^{\mathrm{J}}$ & $20^{\mathrm{GF}}$ \\
\hline 14 & Mass (II) & $1.16^{\mathrm{KJ}}$ & $2.60^{\mathrm{E}}$ & $0.36^{\mathrm{ED}}$ & $20^{\mathrm{GF}}$ \\
\hline 15 & Ezichi & $1.14^{\mathrm{K}}$ & $2.22^{\mathrm{H}}$ & $0.29^{\mathrm{E}}$ & $22^{\mathrm{ED}}$ \\
\hline 16 & E4077 & $2.00^{\mathrm{H}}$ & $1.10^{\mathrm{L}}$ & $0.16^{\mathrm{GF}}$ & $19^{\mathrm{G}}$ \\
\hline 17 & E4197 & $2.50^{\mathrm{D}}$ & $1.30^{\mathrm{J}}$ & $0.95^{\mathrm{A}}$ & $20^{\mathrm{G}}$ \\
\hline 18 & $\mathrm{E} 4212$ & $2.20^{\mathrm{G}}$ & $1.40^{\mathrm{I}}$ & $0.21^{\mathrm{F}}$ & $19^{\mathrm{G}}$ \\
\hline 19 & E4314 & $2.50^{\mathrm{D}}$ & $1.30^{\mathrm{J}}$ & $0.09^{\mathrm{GIH}}$ & $20^{\mathrm{GF}}$ \\
\hline \multirow[t]{4}{*}{20} & E4334 & $2.20^{\mathrm{G}}$ & $1.30^{\mathrm{J}}$ & $0.15^{\mathrm{GFH}}$ & $21^{\mathrm{F}}$ \\
\hline & Mean \pm SE & $2.24 \pm 0.56$ & $2.04 \pm 0.76$ & $0.23 \pm 0.25$ & $21.45 \pm 2.24$ \\
\hline & Prob. & 0.0001 & 0.0001 & 0.0001 & 0.0001 \\
\hline & $\mathrm{LSD}_{0.05}$ & 0.08 & 0.07 & 0.02 & 1.82 \\
\hline
\end{tabular}

*Means followed with the same letter in each column are not significantly different $(\mathrm{p}<0.05)$.

Table 3. Correlation Coefficients among the Physico-chemical and Cooking Quality Characteristics among the Rice Cultivars*

\begin{tabular}{|c|c|c|c|c|c|c|c|c|}
\hline & WUR & GEDC & SICW & OCT & AMY & AMPTN & $\mathrm{GC}$ & GT \\
\hline WUR & 1.00 & $\begin{array}{c}0.293 \\
(0.023)\end{array}$ & $\begin{array}{c}0.255 \\
(0.049)\end{array}$ & $\begin{array}{c}0.397 \\
(0.002)\end{array}$ & $\begin{array}{c}0.060 \\
(0.650)\end{array}$ & $\begin{array}{l}-0.230 \\
(0.077)\end{array}$ & $\begin{array}{l}-0.053 \\
(0.686)\end{array}$ & $\begin{array}{c}0.261 \\
(0.044)\end{array}$ \\
\hline GEDC & & 1.00 & $\begin{array}{c}0.121 \\
(0.356)\end{array}$ & $\begin{array}{c}0.478 \\
(<0.0001)\end{array}$ & $\begin{array}{l}-0.380 \\
(0.003)\end{array}$ & $\begin{array}{l}-0.063 \\
(0.634)\end{array}$ & $\begin{array}{c}0.299 \\
(0.020)\end{array}$ & $\begin{array}{c}0.047 \\
(0.723)\end{array}$ \\
\hline SICW & & & 1.00 & $\begin{array}{c}0.047 \\
(0.722)\end{array}$ & $\begin{array}{c}0.003 \\
(0.983)\end{array}$ & $\begin{array}{l}-0.241 \\
(0.064)\end{array}$ & $\begin{array}{c}0.133 \\
(0.311)\end{array}$ & $\begin{array}{l}-0.064 \\
(0.626)\end{array}$ \\
\hline OCT & & & & 1.000 & $\begin{array}{l}-0.016 \\
(0.904)\end{array}$ & $\begin{array}{l}-0.254 \\
(0.051)\end{array}$ & $\begin{array}{c}0.107 \\
(0.417)\end{array}$ & $\begin{array}{c}0.266 \\
(0.040)\end{array}$ \\
\hline AMY & & & & & 1.000 & $\begin{array}{l}-0.305 \\
(0.018)\end{array}$ & $\begin{array}{l}-0.264 \\
(0.042)\end{array}$ & $\begin{array}{c}0.052 \\
(0.690)\end{array}$ \\
\hline AMPN & & & & & & 1.000 & $\begin{array}{c}0.144 \\
(0.272)\end{array}$ & $\begin{array}{l}-0.070 \\
(0.596)\end{array}$ \\
\hline GC & & & & & & & 1.000 & $\begin{array}{c}0.101 \\
(0.444)\end{array}$ \\
\hline GT & & & & & & & & 1.000 \\
\hline
\end{tabular}

Note: WUR $=$ Water uptake ratio, GEDC $=$ Grain elongation during cooking, $\mathrm{SICW}=$ Solids in cooking water, OCT $=$ Optimum cooking time, $\overline{\mathrm{AMY}}=$ Amylose content, AMPTN = Amylopectin content, GC = Gel consistency, GT = Gelatinization temperature. * Values in brackets indicate probability levels.

\section{Discussion}

Rice varieties with a greater proportion of starch in the form of amylose tend to have a lower glycemic index. Amylose content of milled rice has been found to be positively correlated with hardness values of cooked rice and negatively with stickiness values[10]. Cooking quality of rice mainly depends on amylose content and gelatinization temperature. Amylose contents determine the texture of cooked rice and rice varieties with amylose content of more than $25 \%$ absorb more water and have a fluffy texture after cooking[6]. "Awilo" and "Mass I" had the highest percentage of amylose, while "Faro14 (I \& II)" recorded the least value for percentage amylose, followed by "Mass (III \& II)". This means that "Awilo" and "Mass (I)" will be ideal for the use of diabetic patients, since starchy foods with high amylose level are associated with lower blood glucose level and slower emptying of the human gastrointestinal tract compared to those with low levels of this macromolecule[6].

Feeding with cooked rice high in amylose instead of cooked rice low in amylose may be effective to control serum blood glucose and lipids[13]. More so, Cristiane et al. [14] reported that serum triglyceride and cholesterol levels significantly decreased after consumption of a diet rich in amylose compared to a diet rich in amylopectin (low amylose). Interestingly, amylose and amylopectin are significantly correlated in a negative direction $(r=-0.305, p<0.018)$, indicating that rice varieties high in amylose would invariably be low in amylopectin content. Shin et al.[15] also reported that the high resistant starch (HRS) in rice reduced 
serum cholesterol and LDL cholesterol may be due to resistant starch fermented to produce propionate which reduced serum and hepatic cholesterol. On the other hand, "Faro14 (I \& II)" had the highest percentage of amylopectin followed by "Mass (III \& II)". Amylopectin is composed of glucose molecules with branched links and is less resistant to digestion. This means that rice varieties with a greater proportion of starch in the form of amylopectin tend to have a higher glycaemic index (GI). The starch of waxy rice varieties consists of amylopectin only. These varieties absorb less water upon cooking and have a sticky texture[6]. Foods with a higher GI are, in principle, more quickly digested than those with a lower GI value.

Rice starch is usually digested quite rapidly, compared to other starchy foods such as noodles, sweet potato or cassava. This leads to a prompt and pronounced increase of the blood glucose level (high glycemic index) after the ingestion of rice, similar to that of white bread or pure glucose[6]. Rapid starch digestion is regarded as unfavorable, because fast digestion can cause a sensation of hunger only shortly after the ingestion of rice, and the energy released is quickly used. Therefore, "Awilo" and "Mass I" with the least percentage of amylopectin may be better suited than other varieties in this regard, as it had the highest percentage of amylose which indicates relatively lower glycemic index and could be recommended as appropriate diet for diabetic patients.

In all the rice samples, "E4334" variety had the longest cooking time. The variation in the cooking time could be traced to its gelatinization temperature since gelatinization temperature positively determines the cooking time of rice. It has been asserted that the higher the value of gelatinization temperature, the longer time it takes to cook rice[16]. Indeed, based on this study, significantly positive correlation was observed between gelatinization temperatures and cooking time, though the r-value was low. According to Bhattacharya and Snowbhagya[16], cooking time is primarily related to the surface area of the milled rice and unrelated to other grain properties.

Based on gel consistency classification, all the rice varieties studied could be classified to be medium. However, based on ranking, "Faro 15 (I)" and "E4077" should be said to be harder than others. When cooked, rice types with hard gel consistency harden faster than those with a soft gel consistency. Rice with soft gel consistency cook more tenderly and remain soft even upon cooling. Therefore, "E4197", "Faro14 (II)" and "Onuogwu" would be preferred by consumers due to their tender texture[17]. The correlation between percentage amylose and gel consistency was negative in direction, suggesting the unlikelihood of correlated responses in selecting for these traits.

It is worthy of note that all the newly introduced hybrid varieties showed very low values for grain elongation. Linear elongation of rice on cooking is one of the major characteristics of good rice[9]. Grain size and shape largely determine the market value and consumer acceptance of rice, while cooking quality is influenced by the properties of starch. Some varieties expand more in size than others upon cooking. Length-wise expansion without a corresponding increase in girth is considered a highly desirable rice grain quality trait[9]. In this regard, "China" could be said to be of high quality since it recorded the highest value for grain elongation during cooking. Grain elongation during cooking is affected by over cooking as this may lead to disintegration and curling of the cooked rice grain[18]. In such cases, under cooking could be a recommended option in order to avoid curling of the cooked rice grain[18].

The values for water uptake ratio obtained for the rice varieties were comparable with the values reported by Frei and Becker[6]. "Faro15 (II)" had the highest value of water uptake ratio. Amylose content might be responsible for high water uptake ratio, as Frei and Becker[6] had reported that rice with high amylose content tends to absorb more water upon cooking. This might also be as a result of high moisture content of the rice varieties[19]. However, the correlation between amylose and water uptake ratio was surprisingly not significant. Therefore, the relationship between amylose content and water uptake ratio needs to be clarified in subsequent studies. It is worthy to note that high water uptake ratio affects the palatability of the cooked rice negatively. Solids in cooking water (loss in solids) affect the stability of the cooked rice[18]. The variation in values may be as a result of the variation in rice consistency, seen in the bursting of the grains during and after cooking, as they are of different varieties[20]. "E4197: IR68" variety lost a very high amount of solids in the cooking water. Webb[21] proposed that parboiling of rice grain reduces the rate of disintegration during cooking than the corresponding raw rice. Most of the physico-chemical characteristics (water uptake ratio, amylose, amylopectin, gel consistency and gelatinization temperature) were significantly correlated (positively or negatively) with some of the cooking quality traits (grain elongation during cooking, solids in cooking water, optimum cooking time), which indicates that efforts aimed at selecting rice varieties with improved cooking quality traits would warrant a consideration of the physico-chemical attributes of the rice grain.

\section{REFERENCES}

[1] R. P. Cantral and T. G. Reeves, 2002, The cereal of the World's Poor Takes Center Stage, Science, 296, 53

[2] M. P. Jones, 1995, The rice plant and its environment, WARDA Training Guide, 2, $27-30$

[3] B. O. Juliano and D.B. Bechtel, 1985, The rice grain and its gross composition, Rice Chemistry \& Technology, St.Pauls, MN, USA, 17-57

[4] Y. Pomeranz, 1992, Effect of drying on rice quality, Encyclopedia of Food Science and Technology, 1, 35

[5] E. O. Imolehin and A. E. Wada, 2000, Meeting the rice production and consumption demand in Nigeria with improved technologies, International Rice Commission Newsletter, 49, 
$23-41$

[6] M. Frei and K. Becker, 2003, Studies on the in vitro starch digestibility and glycemic index of six different indigenous rice cultivars from the Philippines, Juornal of Food Chemistry, $83,395-400$

[7] S. Takeuchi, M. Maeda, Y. Gomi, M. Fukuoka and H. Watanabe, 1997, The change of moisture distribution in a rice grain during boiling as observed by NMR Imaging, Journal of Food Science, 33, 281-297

[8] R. L. Whistler, J. N. Bemiller, and E. F. Paschal, 1984, Chemistry and Technology, 2nd edition, Academic Press, New York, 887-889

[9] G. B. Sood and E. A. Sadiq, 1979, Geographical distribution of kernel elongation gene(s) in rice, Indian Journal of Genetics and Plant Breeding 40, 439 - 342

[10] C. M. Perez, B. O. Juliano, C. G. Paschal and V. G. Novenario, 1987, Extracted lipids and carbohydrates during washing and boiling of milled rice, Journal of Starch 39, 386-390

[11] R. R. Little, G. B. Hilder and E. H. Dawson, 1958, Differential effect of dilute alkali on 25 varieties of milled white rice, Cereal Chemistry 35, 111-126

[12] International Rice Research Institute (IRRI), 1980, Alkali digestion, In: Standard Evaluation for rice: International Rice Testing Program, 2nd Ed., IRRI, Manila, 43-44

[13] A. S. Magdy, S. E-B., Hossam, A. M. Mona, T. M. Amera and N.A. Sohir, 2010, Effect of amylose content and pre- germinated brown rice on serum blood glucose and lipids in experimental animals, Australian Journal of Basic and Applied Sciences 4(2), 114-121
[14] C. D. Cristiane, W. Melissa, P.S. Leila, D.S. Gabriele, and A.F. Carlos, 2007, Effect of amylose content of rice varieties on glycemic metabolism and biological responses in rats, Food Chemistry, 105, 1474-1479

[15] C. K. Shin, S. H. Chen, W. C. Hou and H. H. Cheng, 2007, A high-resistance-starch rice reduces glycosylated hemoglobin levels and improves the antioxidant status in diabetic rats, Food Research International 40, 842-847

[16] K. R. Bhattacharya, and C. M. Snowbhagya, 1971, Water uptake by rice during cooking, Journal of Cereal Science Today $16,420-424$

[17] S. X. Tang, G. S. Khush, and B. O. Juliano, 1991, Genetics of gel consistency in rice, Journal of Genetics, 70 (2), 69-78.

[18] B. O. Juliano, A. B. Blakeney, I. Butta, D. Castilli, N. H. Choundhury, T. Iwasaki,N. Shibuya, N. Kongseree, E. T. Lagos, V. S. Murty, C. M. Paule, C. M. Perez and B. D. Webb, 1982 b, International cooperative testing on alkaline digestibility values for milled rice, Starke 34, 21-26

[19] M. Frei and K. Becker, 2004, Agro-biodiversity in Subsistence-oriented farming systems in a Philippine upland region, Biodiversity and Conservation 13, 1591-1610

[20] L. Borasio, 1965, Aspect actual de l' analyse et de l'appreciation des riz, Riso 14, 41-65

[21] B. D. Webb, 1985, Criteria of rice quality in the United States, Rice Chemistry and Technology, 2nd Ed., American Association of Cereal Chemists, $774-776$ 